\title{
Memories of Sounds: An Archiving Project in Two Aural COMmunities
}

\author{
Earl Clarence L. Jimenez
}

PhD, Philippine Women's University; contact: ecljimenez@ pwu.edu.ph

\begin{abstract}
Documentation, collection, and the storage of music and sound is second nature to the discipline of ethnomusicology. Frances Desmore's iconic photograph (albeit staged) of a gramophone with Blackfoot leader, Mountain Chief in the early $20^{\text {th }}$ century quite accurately depicts a salient feature of the discipline --- the scholar and the local engaged in the recording of music. The technology and the dress have obviously undergone changes but the photograph continues to echo resonantly. As Jaap Kunst has said and quoted by Seeger, "Ethnomusicology could never have grown into an independent science if the gramophone had not been invented. Only then was it possible to record the musical expressions of foreign peoples objectively." (Seeger, 1986: 261).
\end{abstract}

\section{Keywords}

Archiving, Aural community, Sound collection, Ethnomusicology, fieldwork

\section{INTRODUCTION}

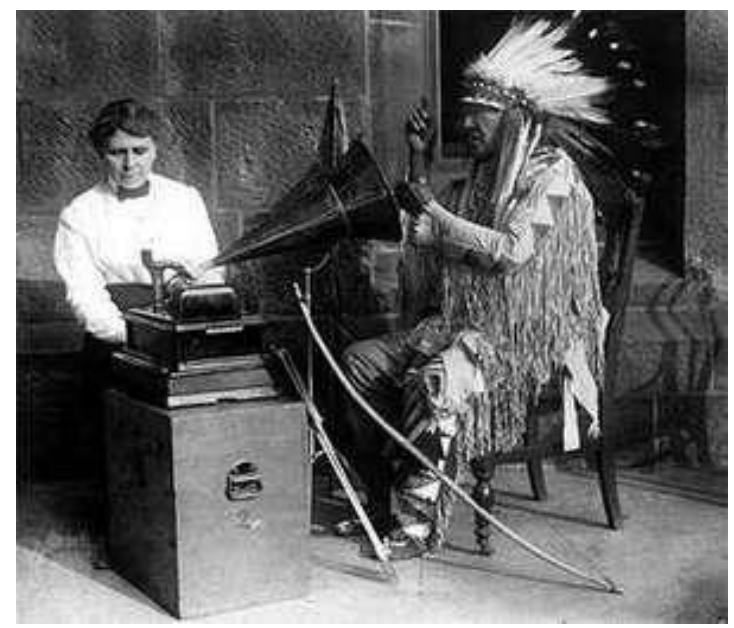

FIGURE 1: Picture of Frances Desmore with Mountain Chief. ${ }^{1}$

Indeed, the discipline has yielded a rich collection of sonic archives all over the world from the legendary Smithsonian recordings to valuable university collections and, of course, the treasured personal collections of scholars. Perhaps, the difference today is that scholars are more cognizant of the impact of one's strategic location and formation, to use the words of Said (2014), with the subjects being studied and the sound and music being collected. Thus, one's exertions in the collection and archiving of sounds are mediated by the scholar's own authority and power over the materials and the meanings these acquire as he configures and analyse these as social and cultural texts.

\footnotetext{
${ }^{1}$ https://www.britannica.com/biography/Frances-Densmore (public domain, last accessed 6 January, 2020). 
My recent work on soundscapes following R. Murray Schafer (1993) and further elaborated by Steven Feld (2015) with the concept of acoustemology has led me to re-examine how I perceive sound archiving. Acoustemology offers an epistemology where sound is a way of knowing. It examines how people engage with the soundscape. Reflecting on these drew me to scrutinize how the collection and storage of sounds as archival material is mediated by the collector's and the performers' engagement with the process of archiving. Archives after all, are not static speechless objects. Following Focault, they are socially constructed by the collector and the collected allowing numerous possibilities of what can and cannot be collected (Focault, 1972). Thus, to archive is to peer into people's configuration of their own culture and practices. Reflexively, archiving affords the opportunity for me to postulate on how to organize, present, and manage the collections and the archives.

I bring these concepts into my work with the sound archives of two disparate communities, the Tboli of Lake Sebu in the southern Philippines, and a religious community in the suburbs of Metro Manila. I refer to these two as aural communities as sound is an inherent part of the lives of the people both individually and communally. These are reflected in particular practices such as in ceremonies and rituals where sound plays important roles. I examine how the process of setting-up the archives and engaging the people to document their own sonic practices allowed them to confront issues of heritage and sustainability, to engage in conversation with themselves as they configure aspects of their culture, and to understand how the process of collection and archiving can be a means to empower themselves. I consider archiving in both the communal and individual levels. Current technologies such as built-in recording features in mobile phones, after all, have allowed individuals to make their own recordings and store them as personal collections to be used in the future for whatever purpose they may serve.

\section{The Tboli of LAKE SeBu}

The Tboli are an indigenous group living in communities in the Allah Valley in the mountains of southern Philippines. Their cultural heartland is Lake Sebu. My archival work with the Tboli of Lake Sebu began in 2019 as a way of giving back to the community. During fieldwork for the past several years, many locals I came across with have bemoaned how they were often the subject of research by outsiders who do not make any effort to make return visits to the community nor give copies of their research outputs once they are done I sought to address this gap by proposing to conduct workshops for the community on how to document their own sonic culture with the eventual goal of establishing an archive at the School of Living Traditions run by Maria Todi, a respected cultural worker and traditional dancer.

I also noticed that many culture bearers make mention of analog and digital recordings in which they have been featured. These run the gamut from informal recordings made by tourists for social media uploading to recordings by researchers, and to a few compact discs that have been made by a few record labels. 


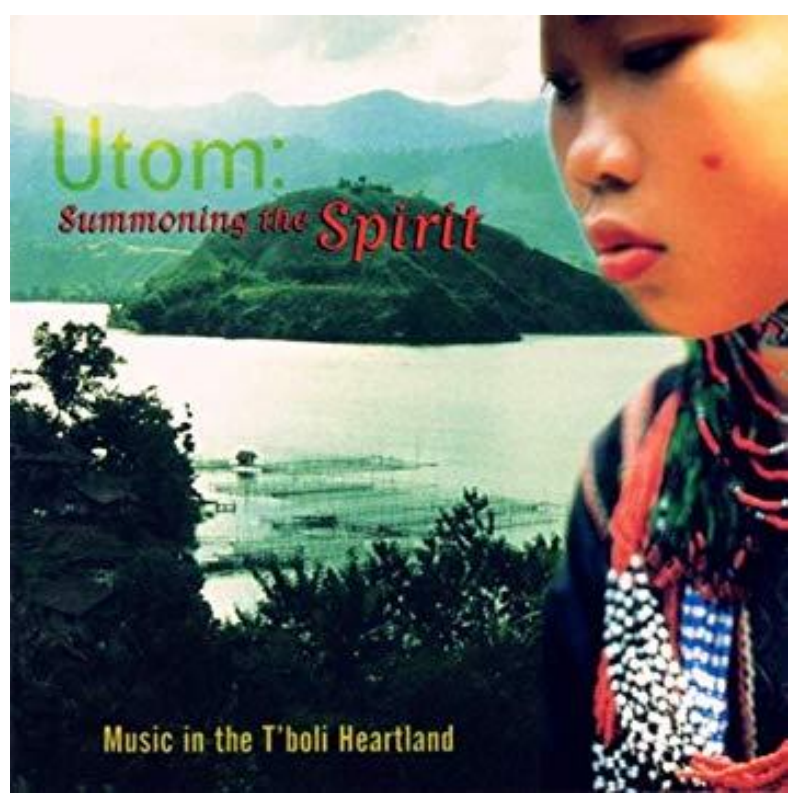

FIGURE 2: The cover of Utom: Summoning the Spirit produced by ethnomusicologist, Manolote Mora, featuring his 1995 field recordings. ${ }^{2}$

Reminiscences by the Tboli of these recordings are almost always accompanied by nostalgia for the music they no longer hear today. In the case of the performers, their nostalgia is director towards those years when they were actively performing. Tboli artists who have attained legendary status owing to their exemplary musical talents and whose voices and instrument playing they hear on the recordings are likewise remembered often with much awe and admiration. Seeing how these have become part of the memory of the community, in a way framing how they remember certain things, I brought a few of these recordings for them listen to it. One afternoon, while listening to Tudbulul Lunay Mugul ${ }^{3}$, a compact disc of the great chanter, Medung Sabal, Joel Genlal, a highly regarded Tboli drummer, recounted her powerful presence each time she would sing. It was a presence that he felt while listening to her plaintive voice talking about the adventures of the mythical hero, Tudbulul. Listening sessions like this inevitably led to talk on the need for recordings to be made by the Tboli themselves and for themselves. For the past years, the Tboli have been increasingly cognizant of their cultural capital and how they are seemingly left behind as researchers partake of these. It was decided that the time had come to take matters into their own hands; hence, Rosie Sula, a Tboli chanter, made arrangements with met to record her songs as she felts her advancing age may eventually lead her to forget these.

Quite a few Tboli have been documenting their own culture. Maria, herself, has her own collection of recordings when she was working as research assistant to the French anthropologist, Nicole Revel, who was then doing work on epic chants. Her nephew, Michael Yambok, a teacher at a public school and a cluster head for southern cultural communities of the National Commission on Culture and the Arts (NCCA) has been actively engaged in cultural mapping through a government grant. Thus, the workshop I developed was meant to supplement the work that people like Maria and Michael have already been doing. To interested Tboli, it would also provide a semblance of formal training.

2 Image (public domain) captured from https://www.amazon.com/Utom-Summoning-Spirit-Music-Heartland/ dp/B0000009R8 last accessed on 6 January, 2020.

3 Released in 2008 by TAO Music, a Philippine recording company known for its albums featuring indigenous musicians. 


\section{Workshop on Sound Heritage Collection and Documentation}

I conducted the first workshop in May in time for National Heritage Month. About 20 people from Lake Sebu and Tboli town were invited by Michael. It was a mixed crowd of college level students, teachers, and a few cultural workers. The two-day workshop was a combination of short lectures on music heritage, and documentation and collection practices. To get an actual feel of these processes, it also included practical activities such as photographing, drawing, and measuring music instruments, and transcribing song texts. The workshop was contextualized within the current availability of resources in the community. Mobile phones, for example, were used as the primary recording tools as these were widely available. I drew-up a simple 5-step process consisting of the following: Inventory, Assess, Choose, Plan, Collect and Document. This was meant to be a rough guide for the community to follow when they finally work on their own.

In the inventory step, participants identify what they consider as their sound heritage. Expectedly, questions on what they consider as originally theirs as opposed to what is borrowed inevitably make their way into the discussion. The assessment step evaluates: current musical practices, the transmission and continuity efforts of individuals and of the community, and the collection and documentation that have been done, whether by themselves or by outsiders. The step involves an evaluative criteria such as: the presence of acknowledged culture bearers or people adept with the music and the music instruments, if was still being heard by the community, if the present generation was familiar with it, if they knew the practices associated with the music making, and so forth. Participants then choose what they want to collect and document, whether it is based on personal preference or community need. In this step, participants also learn to prioritize especially if a particular musical practice is in danger of disappearing or a singer or instrumentalist is already ailing. Planning involves scheduling visits and recording sessions while at the same time being on the lookout for spontaneous opportunities to capture a sonic event. After all these have been done will participants finally engage in collection and documentation following procedures they learned in the workshop.

The participants were grouped according to their areas, Lake Sebu and Tboli town. They were asked to make a quick inventory and assessment of their music. The activity drew varied responses from the different groups. Of interest were the differing opinions on which music they truly valued as their own and which were ones were in need of immediate "rescue." It is crucial at this point to mention that much of the presentation of Tboli culture is in the context of tourism through short "cultural shows" for domestic and international tourists at the different resorts that ring the lake. These shows consist of the playing of a few music instruments such as a boat lute (hegelong), a flute (sloli), a mouth harp (kumbing), a small drum (tnonggong), some dancing, and the singing of an improvisatory welcome song. Infrequent are the singing of epic chants, ritual chants, or even the playing of music instruments in actual contexts. The result is musical forms that seem to have become more privileged than others as far as frequency of performance. The exercise of evaluating their extant music, therefore, allowed the participants to confront these seemingly ignored realities and to realize that certain musics were no longer being performed and heard. 


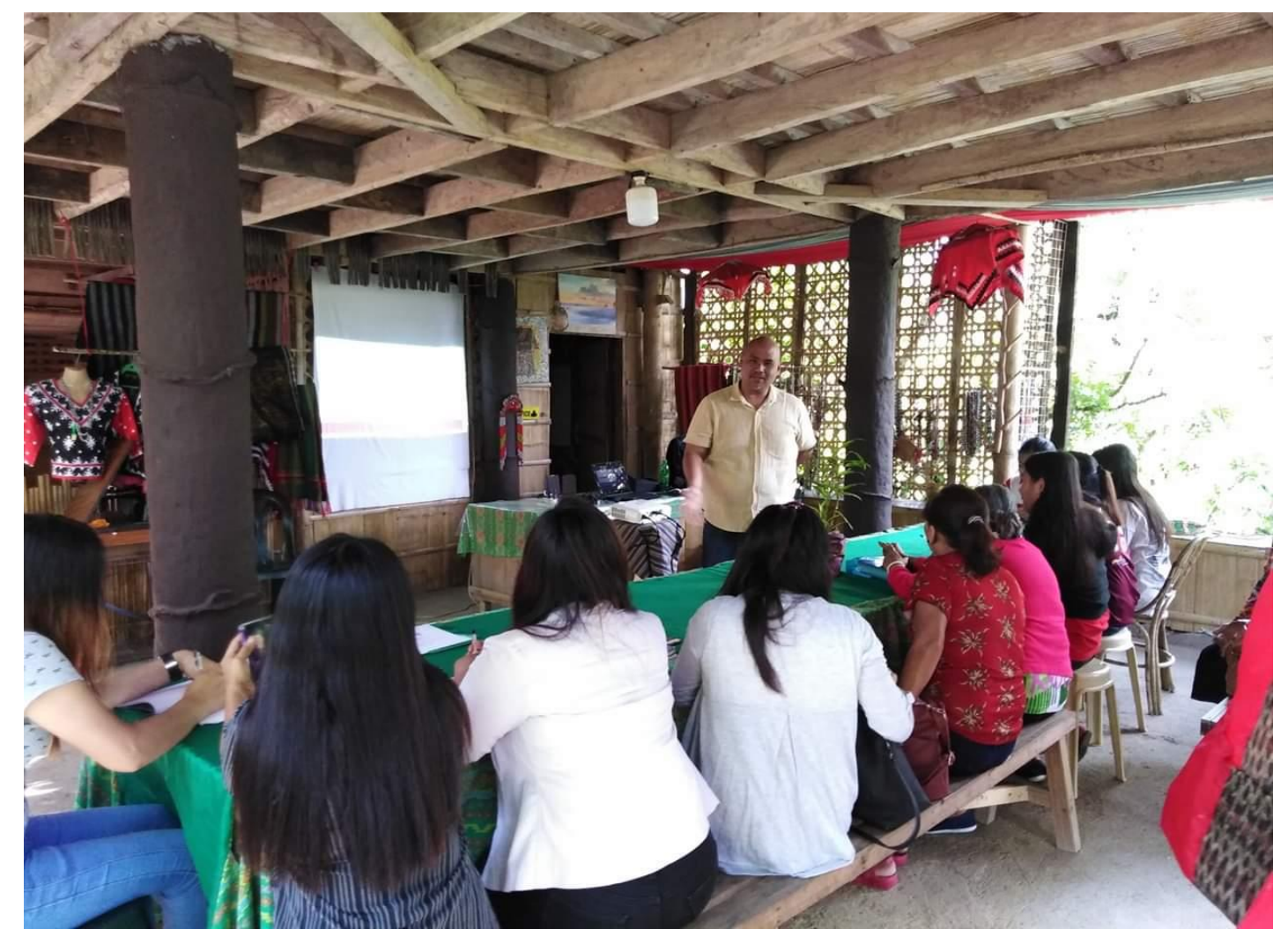

FIGURE 3: The workshop at the School for Living Traditions in Lake Sebu (Photo by the author).

To the much older participants such as Susan Perong, a community leader and cultural division head of Tboli town, the data presented hinted of nostalgia as she recalled many musical practices in the past. It was also an opportunity for elderly people like her to see what the young participants knew about their musical culture. Symbiotically, the younger participants took the chance learn from the older generation and from others who were more knowledgeable about the music. Confronted with their musical cultures, the participants were forced to examine its current state and practice amidst the touristization and commercialization of Lake Sebu, and the continuous influx of migrants which has altered the production and consumption of Tboli culture. Remarks such as "I don't hear that anymore," or "I used to hear it when I was a still a small child" were common when certain songs or musical forms were performed or discussed during the workshop. With many cultural bearers having passed away and along with them their music, the community realized the need to record and archive. The recordings will not only preserve the music, but the presence of the performers themselves. To the Tboli, sound recordings are not just musics and sounds, but auditory presences of people.

The archiving project is still in its premature stage and subsequent workshops are planned. As of now, the Tboli are making recordings of their own music, writing field notes, cataloguing, and storing these. The community is documenting itself, not relying on outside researchers or leaders. They are working towards having a modest storehouse of audio and video recordings of their sound culture---products of their own collection efforts. I share in the belief with the community leaders that an archive resulting from the community's own exertions empowers them as it gives them one more means to map out the future of their own culture. 


\section{SOUND ARCHIVING AND KARAOKE}

One interesting output of the workshop is the discussion on the prevailing soundscape of karaoke in Lake Sebu. The Tboli are acutely aware of their sonic environment which provides fodder for much of their music, particularly instrumental music. However, for the past years, the blare of karaoke and dance music coming from the homes or eateries of lowland migrants, especially late at night, has resulted in tensions as the Tboli complain how it destroys the peacefulness of the surroundings. In the workshop, participants were confronted with reflexive questions such as: do I still hear the sound of birds? Insects? Streams? Waterfalls? All these, after all, are mimicked by musical instruments. The sound archiving project, therefore, engages the community to also record their natural soundscape as part of their intangible heritage. In their push to control the creeping noise pollution they can stake their claim by arguing that the soundscape is much a part of their intangible heritage as their music, dance, beadwork, embroidery, boat-making, and weaving. If they cannot win over the inaction of local authorities to control the noise pollution in spite of existing ordinances, perhaps a sonic heritage approach can help push for this. In addition, with the changing soundscape of Lake Sebu, archival recordings of the environmental sources of Tboli music itself provide a means by which the musical culture can be sustained.

\section{The Holy Church of YahWeh}

The second aural community is a faith community ${ }^{4}$ based in Quezon City, a suburban area north of the capital city of Manila and comprising about 200 members. The community was founded 40 years ago by a woman referred today as the "founding mother" and has since grown to be a formal organization that calls itself The Holy Church of Yahweh. A single independent church not affiliated with any denomination, its religious beliefs and practices are a syncretism of Roman Catholicism, Born Again Christianity, Judaism, Buddhism, and its own beliefs as formulated by the founding mother and later by subsequent leaders upon the death of the latter.

Central to the community is the people's acoustic relationship with sound and music which function as mediators between the divine and the human and by which the people engage and make material their faith. This is manifested in numerous rituals and celebrations such as the weekly "healing of the spirit" sessions in which people actively listen to sermons and loudly articulate prayers as part of the healing process. The content of these sermons includes preachings on the nature of God, practical instructions on one's conduct of life, and trances in which deities such as Diyos Ama (God the Father) speak or sing. As such, the sermons inform the church's collective and the people's own ontology of their faith.

I have been doing work with the community for decades as part of my research in the acoustemology of new religious movements. In working with the church's sound archives I became interested in how these materials came to be used as sonic landmarks of the people's faith and its function in their religious practice.

\footnotetext{
4 The community prefers to refer to themselves as a faith community or a church rather than a religious group as they do not formally identify with a particular religious denomination.
} 


\section{The Collection}

The collection consists of several dozen cassette recordings which have all been digitized. This is part of the larger archive holdings consisting of transcriptions of trances, log books, photographs, artefacts, and numerous paper documents which relate to the history of the community and of the founding mother.

The recordings were made from 1978 to about 1991 by some members so they can listen to the sermons over and over again and share it with others in the belief that one can still receive healing by listening to the recordings even if one is absent during the actual healing session. Since the passing away of the founding mother in 1992, cassette recordings of these sermons have become valuable archival materials to which the people continue to listen to as part of the community's healing practice. The recordings have also become reference materials for church practices and beliefs. When the Church splintered into three groups due to schisms in its leadership, each of these attempted to stake its legitimacy as the rightful church. There was an attempt to gather as many recordings as possible. The faction I am working with is the largest and claims to be the legitimate one as it is the one that adheres most closely to the practices of old. It also has the largest archival collection of recordings which further lends legitimacy to the community's claims. Being the holder of these sonic artefacts from which healing is received and theology is sourced, the archives become the instruments by which power is represented and staked.

\section{ENGAGING WITH THE SOUNDS}

I assist the community in organizing their archives through cataloguing and preservation of their collection, primarily their paper documents and audio recordings. What aroused my interest was the way the sound recordings functioned in the sacred practices of the church. The recordings offer a means for the members to engage with the divine sounds that is believed to emanate from them--- the trances, the voice of the founding mother, and the sounds of objects such as bells that accompany certain ceremonies. More importantly, the recordings allow the Church to continue its weekly healing of the spirit sessions.

The recordings have also become a means for the members to connect with their past often making references such as "... as said on the tape" or "...it's on the tape." In a way, these also function as a means to settle issues on dogma and practices. One only needs to listen to the recordings and hear what the founding mother said about certain issues. For the newer members of the church, listening to the recordings is an opportunity to experience a past that they never experienced, but which they can now claim to be part of. The recordings also give flesh to the founding mother, whom they only know through stories and photographs as video technology video technology was still economically prohibitive during that time. The archival recordings and people's listening practices to it are a means by which communal memory of the founding mother and the church as it was before is revived and sustained.

Corollary to this sound archiving project is the creation of an archive of the church's oral history as narrated by its members, particularly those who have been with the community since the time of the founding mother. While memoirs have been written, the oral narration of events and experiences add a layer of complexity in the narrative as it allows people to relive and describe the aural features of their faith. They are earwitnesses, (to use Schaffer's term) wherein remembrance and testimony are informed by their auditory experiences. 


\section{SUMMARY}

Sonic archival recordings are not mute testimonies of a past. While their inherent value lies in whatever sound recording is encoded in the media, no less muted in value are the stories that shaped these and the people's continuous and sentient engagement with it. As the two case studies show, archives can be dynamic participants in people's everyday lives. If sound can be a way of knowing as Feld tells us, then the archives and its relationship with the people - the scholars and the heirs to these recordings are also a way of knowing. Sound archives, after all, act as a sort of insurance against the fragility of memory and memory holders.

My work with the two communities is still in its primary stages whose structure is largely determined by how the community feels about their own sonic culture and heritage and the path they wish to take. It is a process filled with negotiations on what they deem valuable, what the archives mean to them, and its function as an integral and dynamic part of the community. Reflexively, working with these communities was an opportunity for me to engage with the people in ways far different from what I was more accustomed. It allowed me to examine how I do my archival work and the innumerable ways it impacts the people. Working with the church community gave me the opportunity to examine religiosity from a sonic archiving perspective where archives are part of the quotidian aspects of sacred practice.

What I bring forth to the discipline of sound archiving is a process where archiving ultimately becomes community practice, representing sonic presences, and where people engage with archives not as mere artefacts of past traditions but as materials for sustainability. Sound archives are not just memories of sounds. They are deeply connected to the community itself, evoking presences, articulating beliefs, and sustaining practices.

\section{REFERENCES}

Feld, Steven. "Acoustemology". Keywords in Sound. Edited by David Novak and Matt Sakakeemy. Durham/London: Duke University Press, 12-21.

Focault, Michel. 1972. The Archeology of Knowledge and the Discourse of Language. (A.M. Sheridan Smith, Trans.) New York: Pantheon Books.

Said, Edward. 2014. Orientalism. New York: Knopf Doubleday Publishing.

Schafer, R. Murray. 1993. The Soundscape: Our Sonic Environment and the Tuning of the World. Rochester: Destiny Books.

Seeger, Anthony. 1986. The Role of Sound Archives in Ethnomusicology Today. Ethnomusicology, 30(2): 261-276. 